\title{
HERENCIA, HONOR Y CONFLICTOS FAMILIARES EN EL ARAGÓN DEL SIGLO XVIII"
}

\section{Inberitance, Honour and Familiar Feuds in the Aragon of the 18th Century}

Encarna JARQUE MARTÍNEZ

Universidad de Zaragoza

Correo-e: ejarque@unizar.es

Francisco José ALFARO PÉREZ

Universidad de Zaragoza

Correo-e: fjalfaro@unizar.es

RESUMEN: Rara es la familia que, en un grado u otro, en un momento determinado no experimenta o ha vivido cierta tensión y conflicto entre sus componentes, ayer como hoy. Los motivos por los que aquellos surgieron en el Aragón del siglo XVIII, su incidencia y las distintas soluciones empleadas para ponerles fin centran un estudio en sintonía con las últimas corrientes historiográficas. Junto a una casuística bastante común basada principalmente, aunque no solo, en enlaces conflictivos, malos tratos familiares y disputas por herencias y bienes, la peculiar legislación aragonesa aporta una serie de matices propios que contribuyen a perfilar con mayor nitidez algunos de estos problemas inherentes a la condición humana en todo lugar y momento.

Palabras clave: Familia; tensión; violencia; pleito; legislación; Aragón; siglo XVIII.

* Trabajo realizado dentro de los proyectos del Ministerio de Ciencia e Innovación HAR2012-34576.

(C) Ediciones Universidad de Salamanca / ®@ Stud. his., H. ${ }^{a}$ mod., 38, n. 2 (2016), pp. 137-165 
ENCARNA JARQUE MARTÍNEZ Y FRANCISCO JOSÉ ALFARO PÉREZ

HERENCIA, HONOR Y CONFLICTOS FAMILIARES EN EL ARAGÓN DEL SIGLO XVIII

ABSTRACT: Family conflict was a common experience in past families close as it is today. This study is based on the reason that led to family breaking in the 18th Century Aragon and the lines society prescribed to avoid a total dissolution of a family kin. The most common causes analyzed for these breakdowns were marriage plans, inheritances and domestic violence, all gathered in different lawsuits. Aragonese law affects to these situations in a different way that Castilian law did. The particular interpretations of Aragonese lawyers printed in the lawsuits their perception of human condition.

Key words: Aragon; 18th Century; Family; Conflict; Violence; Lawsuit; Legislation.

El notable desarrollo historiográfico que sobre la familia en la Edad Moderna ha tenido lugar en las últimas décadas no ha tratado de un modo sistemático las variantes violencia y conflicto hasta fechas relativamente recientes. En los primeros momentos la atención estuvo casi monopolizada por cuestiones como las estrategias de reproducción, los lazos de solidaridad o la división del trabajo en el seno familiar. El grueso de los esfuerzos se encaminó a determinar el rol desempeñado por cada uno de los integrantes del núcleo familiar -el cabeza de familia, la esposa, los hijos, las hijas- dentro una jerarquía aceptada tanto por sus miembros como por su entorno social. Preocupados por estos aspectos, los investigadores solían dejar en segundo plano todo lo relacionado con las tensiones familiares, aun cuando las evidencias de su presencia eran abrumadoras, desde el mito bíblico de la muerte de Abel a manos de su hermano Caín, en el seno de la primera familia de la humanidad, hasta la interminable serie de fratricidios o parricidios en las civilizadas clases altas romanas, en las dinastías de las tribus bárbaras, en las patricias familias de los estados pontificios en las estrategias de las familias patricias ${ }^{1}$ para ceñirse o mantener la tiara papal. No es de extrañar, por tanto, que en estos últimos años, tras una temprana aproximación al tema de James Casey ${ }^{2}$, la atención de los especialistas en la historia de la familia -sobre todo desde el ámbito de la historia de género- haya tratado aquellas situaciones

1. Sirva de ejemplo el de la familia Borgia, de origen aragonés. Sobre la misma véase, entre otros, Villarroel González, O.: Los Borgia: Iglesia y poder en los siglos XV y XVI. Madrid, Silex, 2013.

2. Casey, J.: «La conflictividad en el seno de la familia», Estudis, 22, 1996, pp. 9-25.

(C) Ediciones Universidad de Salamanca / ®@ Stud. his., H. ${ }^{a}$ mod., 38, n. 2 (2016), pp. 137-165 
ENCARNA JARQUE MARTÍNEZ Y FRANCISCO JOSÉ ALFARO PÉREZ

HERENCIA, HONOR Y CONFLICTOS FAMILIARES EN EL ARAGÓN DEL SIGLO XVIII

susceptibles de generar conflicto, tales como la distribución del trabajo, el honor, el reparto de los recursos o las derivadas de la cotidianeidad en la vida conyugal ${ }^{3}$.

Esta más tardía atención a la conflictividad doméstica auspiciada desde el marco de la historiografía de género ha llevado, a nuestro entender, a una cierta distorsión al centrar la mirada preferentemente hacia las distintas formas de violencia o coerción sobre la mujer, en su condición de esposa, hija o hermana. No hay que insistir ni hacen falta profundos estudios para aceptar el papel secundario que, por lo general, en la sociedad de la época se reservaba a la mujer -exceptuados casos

3. Vid. el repaso historiográfico que hace en torno a la cuestión Pascua SÁnchez, M. J. de la: «Violencia y familia en la España del Antiguo Régimen», Estudis: Revista de historia moderna, 28, 2002, pp. 77-102. De la misma autora debe consultarse igualmente «Desórdenes familiares en el siglo XVIII hispánico", en Serrano Martín, E. (Coord.): Felipe V y su tiempo: congreso internacional, Vol. 1, 2004, pp. 631-652; «Violencia y familia en la España moderna», en Actas de la XI reunión científica de la Fundación Española de Historia Moderna. Granada, 2012, pp. 127-157 y «Las relaciones familiares, historias de amor y conflicto», en MoRANT, I. (Dir.): Historia de las mujeres en España y América Latina, II. Madrid, Cátedra, 2005, pp. 287-317. Véanse también estudios como Bossy, J. (Ed.): Disputes and Settlements. Law and buman relations in the west. Cambridge, CUP, 1983; CóRDOBA DE LA LLAVE, R. (Coord.): Mujer, marginación y violencia entre la Edad Media y los tiempos modernos. Córdoba, 2006; Fargas Peñarocha, M.: «Hacia la autoridad contestada: conflictividad por la dote y familia en Barcelona (XVI-XVII)», Investigaciones Históricas, 30, 2010, pp. 99-118 y «De conflictos y acuerdos: la estrategia familias y el juego del género en la época moderna», Anuario de Hojas de Warmi, 16, 2011, pp. 1-18; García GonzÁlez, Fco.: «Las dimensiones de la convivencia. Ciudades y hogares en España, siglos XVIII-XIX», Revista de Historiografía, 16, 2012, pp. 24-43 y García Gonzalez, Fco. y Gómez Carrasco, C.: «Tensión familiar y conflictividad social en la España meridional: el ejemplo de Albacete, 1700-1830», en Bellavitis, A. у СНАвот, I. (Coords.): La justice des familles:autour de la transmission des biens, des savoirs et des pouvoirs (Europe, Nouveau monde, XIIe-XIXe siècles). Ecole Française de Rome, 2011, pp. 263-286; o los de Ortega López, M.: «Protestas de las mujeres castellanas contra el orden patriarcal privado durante el siglo XVIII", Cuadernos de Historia Moderna, 19, 1997, pp. 65-89 y «Violencia familiar en el pueblo de Madrid durante el siglo XvII»", en Cuadernos de Historia Moderna, 31, 2006, pp. 7-37; entre otros muchos. En el caso de Aragón, véanse Alfaro Pérez, Fco. J. (Coord.): Familias Rotas. Zaragoza, 2014; Baldellou Monclús, D.: «El valor de los esponsales: Estrategias y conflictos familiares entre la montaña y el llano aragonés (s. XVIII)», en Pérez Álvarez, M. ${ }^{a}$ J. y Martín García, A. (Eds.): Campo y campesinos en la España Moderna. Culturas politicas en el mundo hispano. Madrid, Fundación de Historia Moderna (CD), 2012, pp. 1038-1048 $\mathrm{y}$ «Los conflictos matrimoniales en las familias y estructuras de poder del Alto Aragón en el siglo XviII", Tiempos Modernos: Revista Electrónica de Historia Moderna, 8:9, 2014, 29 pp.; Charageat, M.: La délinquance matrimoniale. Couples en conflit et justice en Aragon. París, Publications de la Sorbonne, 2011; Jarque Martínez, E. y Alfaro Pérez, F. J.: Caïn et Abel. Conflits fraternels au Royaume d'Aragon (XviIIe et XIXe siècles), en BoudjaABA, F. (Coord.), Frères et sœurs du Moyen Âge à nos jours. Ed. Peter Lang, 2016 (en prensa); o Salas Auséns, J.: «La Cenicienta no era un cuento», en Alfaro Pérez, F. J. (Coord.): Familias Rotas. Zaragoza, 2014, pp. 169-208.

(C) Ediciones Universidad de Salamanca / ®@ Stud. his., H. ${ }^{a}$ mod., 38, n. 2 (2016), pp. 137-165 
ENCARNA JARQUE MARTÍNEZ Y FRANCISCO JOSÉ ALFARO PÉREZ

HERENCIA, HONOR Y CONFLICTOS FAMILIARES EN EL ARAGÓN DEL SIGLO XVIII

o momentos concretos (como puede ser en ocasiones durante la viudedad) ${ }^{4}$-; ni tampoco para dar por bueno que su débil posición la predisponía a ser víctima de abusos en el entorno familiar ${ }^{5}$. No obstante, ello no quiere decir que la violencia o la coerción se dirigiera exclusivamente hacia el género femenino o que las relaciones conflictivas lo fueran entre personas de distinto sexo. La tensión podía surgir entre cualquier miembro de la familia, independientemente de su posición jerárquica, de su edad o de su sexo: las hubo entre los cónyuges ${ }^{6}$, entre padres e hijos $^{7}$ y desde luego entre hermanos, tanto en vida de sus progenitores como, lo que sería más frecuente, tras la muerte de aquellos.

Dichos conflictos siguieron derroteros bien diferentes. En ocasiones a través de cauces sumidos en la violencia más irracional, aunque habitualmente seguían otras formas más «civilizadas», como la intercesión de un arbitraje de terceros -parientes, amigos, autoridades eclesiasticas- o, si esto no surtía efecto o si el objeto de conflicto era importante, con los pertinentes recursos a los tribunales civiles y eclesiásticos. Formas de proceder estas últimas, de las que ha quedado un buen rastro documental sobre el Aragón del siglo XVIII ${ }^{8}$.

4. La viudedad de la mujer en Aragón y en Navarra estuvo marcada en cierta medida por las legislaciones forales de cada territorio y que podrían considerarse como menos perjudiciales en relación con otros lugares. No obstante, no puede generalizarse; hubo lugares en los que, al igual que en puntos de Valencia, por ejemplo, se imponía el «año de manto». Por no mencionar las notables diferencias entre el ámbito rural y el urbano, donde las más de las veces la viudedad femenina iba aparejado a estrecheces económicas. Vid. Ramiro Moya, F.: Mujeres y trabajo en la Zaragoza del siglo XVIII. Zaragoza, 2012.

5. Mantecón Movellán, T. A.: «Hogares infernales: una visión retrospectiva sobre la violencia doméstica en el mundo moderno", en Lorenzo Pinar, F. J. (Ed.): La familia en la historia. Salamanca, 2009, pp. 187-230.

6. Vid. Lorenzo Pinar, F. J.: «Actitudes violentas en torno a la formación y disolución del matrimonio en Castilla durante la Edad Moderna», en Fortea, J. I., Gelabert, J. E. y Mantecón, T. A. (Eds.): Furor et rabies. Violencia, conflicto y marginación en la Edad Moderna. Santander, 2002, pp. 159-182.

7. El papel secundario de la mujer ya venía señalado por los tratadistas de la familia cristiana como el padre Arbiol, A.: La familia regulada. Zaragoza, 1715 (ed. fac. con introducción de Roberto FERNÁNDEZ. Zaragoza, Institución Fernando el Católico, 2000). Estudia este tipo de conflictos para el caso navarro UsunÁriz GARAYOA, J. M. ${ }^{a}$ en «Cuando la convivencia es imposible: Los pleitos de discordia entre padres e hijos (Navarra, siglos XVI-XVII)», en UsUnÁrIZ GARAYOA, J. M.a y GARCía Bourrellier, R. (Eds.): Padres e hijos en España y el mundo hispánico. Siglos XVI y XVII. Madrid, 2008.

8. El presente es un caso más en el que las fuentes marcan los límites del trabajo. Desaparecidos en el caso zaragozano -que no de todo Aragón- los procesos criminales, los más de doscientos pleitos civiles en apelación trabajados en este artículo tratan lo que podríamos denominar como «conflictividad civilizada». Esto es, aquella dirimida ante los tribunales de justicia civiles o eclesiásticos. Algunas denuncias de siglos anteriores han sido analizadas por CUARTERo ARINA, R.: Mujeres transgresoras: el delito sexual en la Zaragoza de los siglos XVI y XVII. Tesis doctoral dirigida por E. Solano CAmón y defendida en la Universidad de Zaragoza el año 2013.

(C) Ediciones Universidad de Salamanca / ®@ Stud. his., H. ${ }^{a}$ mod., 38, n. 2 (2016), pp. 137-165 
ENCARNA JARQUE MARTÍNEZ Y FRANCISCO JOSÉ ALFARO PÉREZ

HERENCIA, HONOR Y CONFLICTOS FAMILIARES EN EL ARAGÓN DEL SIGLO XVIII

\section{Derecho aragonés y tradición Cultural. FóRMulas legales para PREve- NIR EL PLEITO}

Durante la guerra de Sucesión, el reino de Aragón perdió, en 1711, su aparato institucional, incluidos sus fueros, suprimido todo por los Decretos de Nueva Planta firmados por Felipe V. Sin embargo, recuperaría su derecho privado que -tal como se contemplaba en los Fueros y Observancias del Reyno de Aragón- en esta materia apenas había experimentado modificaciones desde los siglos XIII y xiv. Este fue por tanto el marco legal en el que se dirimieron los pleitos aquí trabajados, corpus legislativo en el que perviven aún en nuestros días notables diferencias respecto al vigente en otros territorios peninsulares como el castellano. Sería el caso, por ejemplo, de algunas discriminaciones que pudiéramos llamar positivas para la mujer, tales como el fuero «Quod mulieres pro debitis civilibus non capiantur» aprobado en las Cortes de Zaragoza de 1442, cuyo texto decía literalmente: «Item, querientes haver compasión del linaje femenil, en virtud del dito poder, statuecen e ordenan que muller alguna, por contracto o deudo civil que de aquí avant se fará o se contractará no pueda seyer presa o presa detenida» ${ }^{9}$. En esa línea estaría también una de las claúsulas del fuero «De testibus» (Cortes de Calatayud de 1461), que dispensaba a las mujeres llamadas a declarar como testigos en los juicios la obligación de decir la verdad. Normas como esta o las relativas a los derechos de viudos y viudas situaban a la mujer en una posición más favorable a la que tenía en otros ámbitos peninsulares. Pero las posibles ventajas podían diluirse completamente en el seno de la familia. En las relaciones marido-mujer se daba por sentado el sometimiento de ellas, guardando una jerarquía «natural» aceptada por los poderes públicos y por la todopoderosa iglesia, por la que, además, el varón podía corregir perfectamente a su esposa con procedimientos «proporcionados» acercándose ocasionalmente al umbral (no siempre traspasado) del maltrato. Es la posición evidenciada en algunos textos dieciochescos de gran éxito como, entre otros, La familia regulada, del padre Antonio Arbiol, donde pueden leerse expresiones como: «Considere el varon prudente su dignidad y compadezcase de su muger por su natural imbecilidad y flaqueza», en los que llegaban a tolerarse y aun justificarse los malos tratos para vencer la resistencia de la esposa por grado o por fuerza ${ }^{10}$. Y similar era la actitud de la iglesia en lo tocante a las relaciones

9. Savall, P. y Penén, S.: Fueros, Observancias y Actos de Corte del reino de Aragón. Zaragoza, 1866 (ed. fac. Zaragoza, El Justicia de Aragón, 1991, p. 213). Para las normas relativas a la familia puede verse Jarque Martínez, E.: «Derecho aragonés y pleitos familiares en el siglo XVIII», en Alfaro Pérez, FCo. J. (Coord.): Familias Rotas. Zaragoza, 2014, pp. 15-46 y Salas Auséns, J. A.: «Pero si ..., y si ..., por si .... Asegurar la pervivencia de la casa en el Alto Aragón en la Edad Moderna», en Obradoiro de Historia Moderna, 24, 2015, pp. 225-255.

10. Arbiol, A.: La familia regulada, op. cit., lib. II, cap. VIII, p. 83.

(C) Ediciones Universidad de Salamanca / ®@ Stud. his., H. ${ }^{a}$ mod., 38, n. 2 (2016), pp. 137-165 
ENCARNA JARQUE MARTÍNEZ Y FRANCISCO JOSÉ ALFARO PÉREZ

HERENCIA, HONOR Y CONFLICTOS FAMILIARES EN EL ARAGÓN DEL SIGLO XVIII

paternofiliales. El propio Arbiol justificaba así: «el que perdona a la vara y a la disciplina aborrece a su hijo» ${ }^{11}$ las penas corporales. Pero este proceder no fue exclusivo del mundo eclesiástico. La actitud de las autoridades públicas consentían, toleraban y eran cómplices del mismo modo al mirar para otro lado de acuerdo a un modelo cultural muy arraigado. Muestra de ello es la instrucción dada a los corregidores en 1788 exponía que no debían ingerirse en lo que sucediera de puertas a dentro en las familias: «Se abstendrán los corregidores de tomar conocimiento de oficio en los asuntos internos de padres e hijos, marido o mujer, o de amos o criados, cuando no haya queja grave ni escándalo, para no turbar el interior de las casas, pues antes bien ellos deben contribuir a la quietud y sosiego de ella» ${ }^{12}$.

Las tensiones solían aflorar, especialmente, en dos situaciones: la tocante a la autoridad de los padres sobre los hijos y la relativa a la transmisión de bienes. Sobre la primera, el derecho aragonés no deja lugar a dudas: «Item, de consuetudine Regni non habemus patriam potestatem ${ }^{13}$; y, en lo relativo a la repartición de la herencia, los padres aragoneses, al igual que los navarros, disponían prácticamente con total libertad de sus bienes, obligados a reservar tan solamente 5 sueldos en dinero y 5 en tierras blancas -monto total que podía equivaler, como mucho, al salario de dos días de un oficial artesano, es decir casi nada- para cada uno de los hijos o, si estos faltaban, a los habientes derecho ${ }^{14}$. El total margen de maniobra

11. Idem, p. 451.

12. Cit. en Ortega López, M.: «Protestas de las mujeres castellanas contra el orden patriarcal privado durante el siglo XVIII», op. cit., especialmente las páginas 67 a 82.

13. Savall, P. y Penen, S.: Fueros, Observancias y Actos de Corte del Reino de Aragón. Zaragoza, El Justicia de Aragón, 1991, vol. II, p. 14a. Del alcance del fuero sobre la patria potestad en Aragón, vid. García Atance, M.: «De consuetudine Regni non habemus patriam potestatem», Anuario de Derecho Aragonés, VI, 1951-1952, pp. 157-172. Una interpretación literal de esta observancia llevaría a negar cualquier tipo de autoridad paterna sobre los hijos, incluido el derecho/deber de protegerles y educarles, pero su sentido no era ese. Así entendida repugnaría al derecho natural. Al igual que en el derecho común francés el sentido y alcance de la observancia aragonesa era limitar la patria potestad tal como se entendía en el derecho romano, que reconocía únicamente al padre la condición de sujeto jurídico de la familia otorgándole un poder prácticamente absoluto sobre el resto de los miembros. En el caso aragonés, el poder de los padres sobre los hijos no iba más allá que sobre la educación y la corrección de sus costumbres. Aquellos podían demandar a los miembros de la familia respeto y obediencia, nunca servidumbre. El derecho común francés tampoco recoge la patria potestad, vid. BouRJON, F.: Le droit común de la France et la coutume de Paris. París, 1770, titre I Des personnes libres.

14. Salvo Navarra, que en este punto tenía una legislación similar a la aragonesa, en el resto de los territorios hispanos los padres tenían que reservar una parte significativa de su patrimonio para repartirla igualitariamente entre todos sus hijos (Vid. Alfaro Pérez, Fco. J.: «Ordenamiento foral y realidad socioeconómica de la mujer navarra (siglos XIV-XIX)», en Salas Auséns, J. A. (Coord): Logros en femenino. Mujer y conflicto social en el valle del Ebro, siglos XIV-XVIII. Zaragoza, Prensas Universitarias de Zaragoza, 2013, pp. 241-278). En el caso

(C) Ediciones Universidad de Salamanca / ®@ Stud. his., H. ${ }^{a}$ mod., 38, n. 2 (2016), pp. 137-165 
de que en la práctica disponían los progenitores daba lugar a situaciones muy variadas, influidas por distintos factores, tanto los personales -afectos, enfrentamientos paternofiliales, donaciones hechas con anterioridad, normalmente a la hora de dotar a los hijos en el momento del matrimonio- como las costumbres, diferentes de unas zonas a otras, con áreas donde desde la Edad Media se había ido imponiendo la transmisión de los bienes inmuebles a un heredero único, frente a otras en las que la tradición observada mayoritariamente era la de reparto igualitario (Vid. Mapa 1).

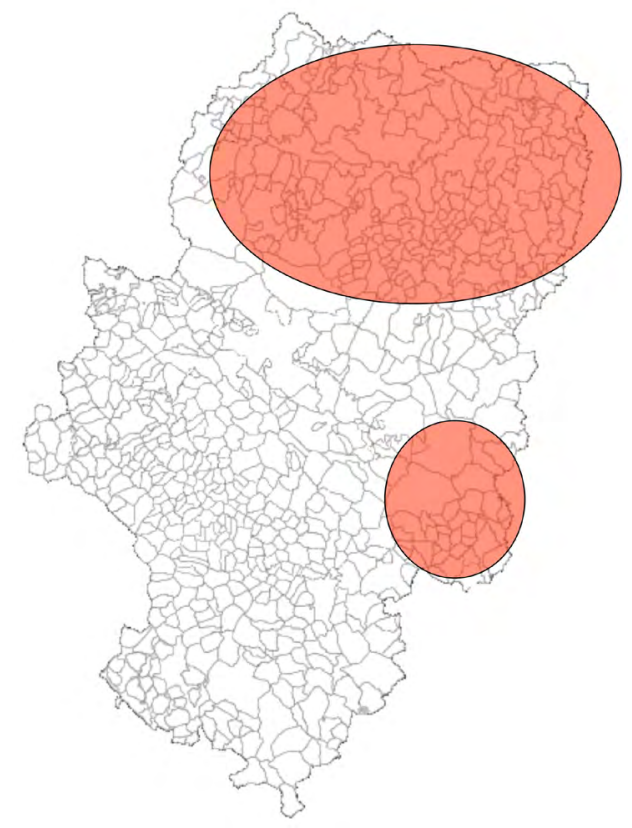

Mapa 1: Áreas de predominio de heredero único en el Aragón de la Edad Moderna.

de Castilla, los progenitores podían disponer de un quinto, además de un tercio de las partes restantes para mejorar a uno o alguno de sus hijos o hijas, debiendo distribuir igualitariamente el resto de sus bienes entre toda su prole (libro X, Título VI, De las mejoras del tercio y del quinto a favor de los hijos y descendientes, Novísima Recopilación. Madrid, 1805, pp. 30-32). En Cataluña, desde 1585 los padres disponían libremente de tres cuartas partes de sus bienes, y tenían que repartir a partes iguales entre todos sus hijos lo restante en concepto de legítima. En Valencia y Mallorca la legítima, a repartir a partes iguales entre los hijos, suponía un tercio de los bienes y la mitad en el caso de que el número de hijos fuera más de cinco. Vid. Rey Castelao, O.: «Femmes et héritage en Espagne au xvire siècle: Stabilité légale et changements réels», XVIIe. Siècle, 244, 61 année, n. . 3, 2009, pp. 457-458. 
En la zona norte del reino -valles pirenaicos, Somontano y Monegros, valle del Cinca- y del Bajo Aragón -las comarcas del Matarraña y Guadalope- predominaba el sistema de heredero único, mientras que en resto del reino era habitual el reparto igualitario. No obstante, junto a este esquema tan rígido, encontramos múltiples variantes precisamente favorecidas por ese amplio margen de maniobra de los padres. Allí donde se testaba a favor de uno de los hijos, no necesariamente el varón, se le solían dejar normalmente los bienes inmuebles, en muchos casos prometidos ya previamente como donación «propter nuptias», en su capitulación matrimonial, disponiendo para los demás dotes en dinero o en ganado, en una cuantía variable, normalmente proporcional a la disponibilidad de la casa. En el resto del territorio, el reparto igualitario coexistía con otras variantes: dejar la herencia al cónyuge supérstite, con libertad para repartir entre los hijos en función de su comportamiento, dando «a qual más, a qual menos a qual nada», expresión corrientemente utilizada en los testamentos; apartar determinados bienes de toda índole -ropas, dinero, joyas, utensilios de trabajo, censales, animales, casas, fincas-, reservándolos como gracia especial para terceras personas o para un hijo concreto o destinar toda la fortuna a la salvación del alma. El asunto resultaba todavía más complejo, pues tampoco era raro que parte de los bienes destinados a los hijos se les hubieran ido entregando en el momento en que estos firmaban las capitulaciones matrimoniales.

Las decisiones de los padres sobre el destino de sus bienes, motivo de posible desigualdad entre los hermanos, estaba en el origen de muchos de los conflictos fraternales, pero también había otras razones que podían llevar al enfrentamiento, entre las cuales el anuncio de matrimonio de uno de ellos con alguien considerado de inferior condición, la inobservancia de algunas estipulaciones testamentarias, el incumplimiento de las disposiciones previstas para los hermanos desfavorecidos por parte del elegido como heredero y, también con frecuencia, la ausencia de testamento ${ }^{15}$.

En previsión de conflictos y para evitarlos, los padres o los propios hermanos ponían en marcha distintas estrategias. Unas veces en forma de renuncia expresa a reclamar ningún otro bien del patrimonio familiar, más allá del que sus familiares le daban en un momento concreto, normalmente en el momento de firmar la capitulación matrimonial. La claúsula de renuncia era frecuente en las zonas de heredero único. Por lo general aparecía entre las condiciones impuestas por los padres de la novia, que debía conformarse con aportar al matrimonio solo la

15. En Castilla los procesos judiciales debidos a disputas familiares sobre testamentos era la segunda causa de litigios, llegan a suponer en torno al 26\% de los pleitos en KAGAN, R.: Pleitos $y$ pleiteantes en Castilla, 1500-1700. Salamanca, Junta de Castilla y León, p. 116.

(C) Ediciones Universidad de Salamanca / ®@ Stud. his., H. ${ }^{a}$ mod., 38, n. 2 (2016), pp. 137-165 
ENCARNA JARQUE MARTÍNEZ Y FRANCISCO JOSÉ ALFARO PÉREZ

HERENCIA, HONOR Y CONFLICTOS FAMILIARES EN EL ARAGÓN DEL SIGLO XVIII

dote que se le asignara, renunciando a cualquier otro derecho sobre los bienes familiares. Pero también hay casos en que esta condición se imponía al novio, y sirva de ejemplo la capitulación pactada entre las familias de Lucas Brun y su prima Valentina Lapetra, ambos vecinos de Urdués, en la diócesis de Jaca. El hermano y la madre del novio, viuda, le daban 30 libras y la mitad del coste de la dispensa matrimonial a su consanguinidad con la novia, a cambio de la renuncia a cualquier otro derecho sobre el patrimonio familiar ${ }^{16}$.

Los testamentos también podían incluir claúsulas destinadas a evitar posibles conflictos entre los descendientes, en ocasiones precisando que el beneficiario solo tenía derecho a los bienes que se indicaban -caso de Clara Villanova, vecina de Fraga (Huesca) a quien su hermano, el presbítero José Villanova y Bardaxi destinaba 720 libras «con cuya cantidad ella se haya de dar por contenta y pagada» ${ }^{17}-$, e incluso amenazando con la pérdida de bienes ya comprometidos, caso del testamento del Felipe Guallart, vecino de Panticosa, que dejaba heredera a su hija María, prefiriéndola a sus hijos Felipe y Miguel. A este último le asignaba 100 libras jaquesas, pero con el compromiso de vivir en la localidad y advirtiéndole «que no busque inquietudes ni rumores en mi casa y a quien yo la dejo, ni menos en mi hacienda», so pena de perder esa cantidad ${ }^{18}$.

Otra de las vías empleadas para evitar posibles conflictos entre los hermanos al fallecer sus padres era la de dejar el reparto de bienes en manos de terceros. En las áreas en que predominaba la asignación de los bienes inmuebles a un solo beneficiario, no son raras las disposiciones que, en ausencia de testamento, responsabilizaban del reparto de la herencia a terceros. Es lo previsto en la capitulación pactada entre la madre de José Puyuelo, labrador de Salas Bajas (Huesca) y el padre, la hermana y el cuñado de Gracia Bistué, para el matrimonio de José y Gracia. Entre las numerosas claúsulas se estipulaba que si morían con descendencia sin testar «entren a nombrar heredero ... el retor que es y por tiempo será de Salas... con dos parientes, y los tres o la mayor parte de los tres, juntándose para dicho fin los tres, hayan de nombrar y nombren herederos de los bienes a uno de los mencionados hijos o hijas» ${ }^{19}$, requisito parecido al empleado en la capitulación de Juan Lafuente, vecino de Gavín, y María Ezquerra, natural de Basarán, obligados

16. Archivo Histórico Provincial de Huesca [en adelante AHPH], Notario Juan José Araguás, 21-10-1721, fols. 94-95.

17. Testamento del año 1752 de José Villanova, incluido en el pleito incoado por Antonia Villanova contra su hermano Gregorio, Pleitos Civiles, caja 3.898-5 (1791), caja 4.570-6, año 1766.

18. AHPH, Testamento de Felipe Guallart, 1647.

19. AHPH, Notario Francisco del Carmen, 15/4/1760, fols. 59-62.

(C) Ediciones Universidad de Salamanca / ®@ Stud. his., H. ${ }^{a}$ mod., 38, n. 2 (2016), pp. 137-165 
ENCARNA JARQUE MARTÍNEZ Y FRANCISCO JOSÉ ALFARO PÉREZ

HERENCIA, HONOR Y CONFLICTOS FAMILIARES EN EL ARAGÓN DEL SIGLO XVIII

a elegir un heredero entre sus hijos, «aquel que mejor pareciere a los padres y en falta de estos podrán hacer dicho nombramiento dos deudos de cada parte y el cura temporal de Gavin y disponer de lo demás que tuvieren por conveniente para el bien de la casa y que podrán disponer todos juntos o la mayor parte» ${ }^{20}$.

También buscaba evitar el conflicto el pacto amistoso entre los hermanos en el momento de repartir la herencia. Es lo que intentaron Vicente, Joaquín, Lucía, Eusebia y María tras la muerte de sus progenitores, Juan Martín y Catalina Cabrera. Inicialmente los hermanos se daban por satisfechos con la división de bienes prevista y acudían a un escribano para que elevara la correspondiente escritura, acto que no llegaría a formalizarse por no poder estar presente alguno de los implicados ${ }^{21}$; es asimismo lo que firmaron los vecinos de Alcorisa (Teruel) Pedro y Melchora García, hijos de Manuel y Francisca San Juan, fallecidos sin testar. Pedro y Melchora firmaban ante notario en 1762 una carta de partición de bienes, donde dejaban claro el motivo de la misma: «Para evitar de questiones y pleitos entre nosotros dichos otorgantes, tenemos combenido en otorgar amigablemente la presente escritura de partición $»^{22}$.

Una salida parecida es la que se practicaba en el Somontano oscense donde la vía para solucionar los conflictos era dejar las diferencias en manos de terceros, cuyas decisiones las partes enfrentadas se comprometían a respetar, bajo cuantiosas penas pecuniarias sobre aquel que no lo hiciera. Sería el caso del proceder a la muerte de Vicente Gastón, alias Pérez, quien no había testado. Vicente de Sasso y su esposa Isabel Gastón, alias Pérez, de una parte, y Martín Gastón, alias Pérez, del lugar de Ayera se enzarzaron en «malas y desonestas palabras, razones, pláticas y rinyas», pero para evitar "pleitos, quistiones, diferencias, demandas y controversias así civiles como criminales», acordaron ponerse en manos de mosen Francisco Viñuales, vicario de Junzano y mosen Miguel Viñuales, racionero de Sieso. El fallo en este caso designó heredera de los bienes del difunto a Isabel, pero a la vez le obligaba a entregar a la otra parte determinadas cantidades, por los gastos habidos en los funerales y en compensación al tiempo que el difunto había estado en casa de Martín Gastón trabajando como pastor a beneficio propio. El fallo obligaba a las partes y su incumplimiento conllevaba la pena previamente pactada de 2.000 ducados $^{23}$.

20. Archivo Histórico Provincial de Zaragoza [en adelante AHPZ], Pleitos Civiles, caja 3.898-5, año 1791.

21. AHPZ, Pleitos Civiles, caja 763-2, año 1818.

22. Idem, caja 4.641-6, año 1763.

23. AHPH, Notario Miguel de Mur, año 1586, Protocolo 00943, 30 de enero de 1586, fols. 56-60.

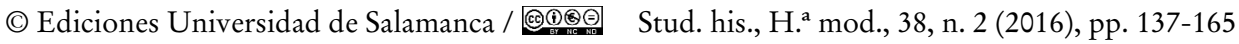


En capitulaciones matrimoniales y testamentos de las zonas de heredero único también podían aparecer claúsulas para salvar las posibles desavenencias entre los padres, señores mayores, y el hijo y la nuera, en caso de que la convivencia bajo un mismo techo resultara imposible ${ }^{24}$. Sirva de ejemplo la condición inserta en la capitulación matrimonial de Martín Viñuales y Lorenza Viñuales. Los padres de Martín le nombraban heredero «para después de sus días», reservándose ser «señores mayores» de por vida, viviendo todos bajo el mismo «y si acasso hubiere entre los dichos padre, madre, hija y yerno algún roydo o rinya que no puedan a una vivir, que dicho roydo o rinya haya de ser visto y connoscido por quatro hombres parientes más cercanos tomados cada dos por cada parte y estar a todo lo que dichos quatro hombres dirán, pronunciarán, declararán y determinarán y no a otra cosa» ${ }^{25}$.

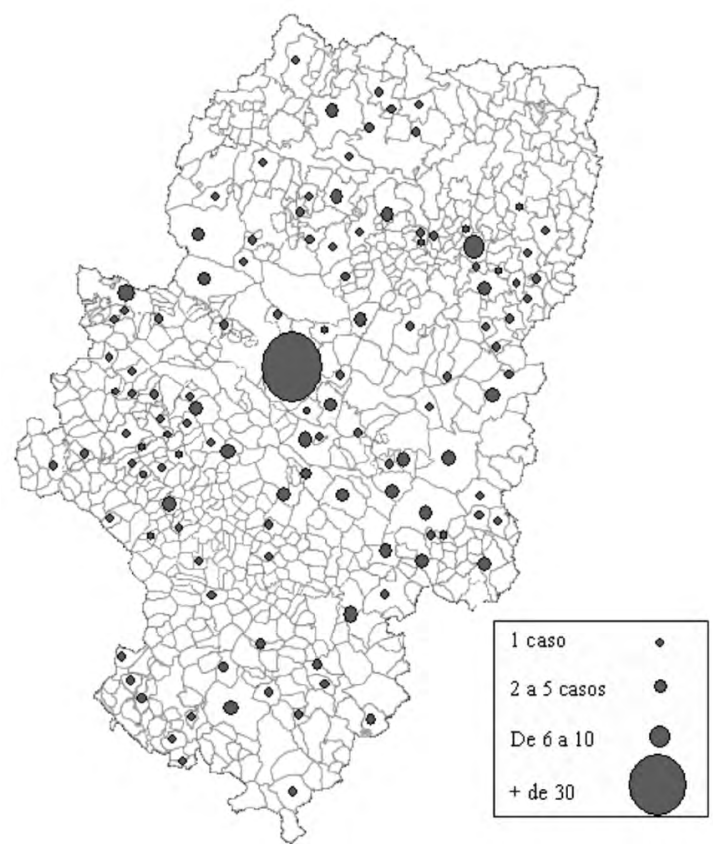

MAPA 2: Localización y número de pleitos incoados entre hermanos en las localidades aragonesas de los siglos XviII y xix.

24. Vid. Ramiro Moya; Fco.: y Salas Auséns, J. A.: «Mujer y transmisión de la propiedad en el Aragón moderno», en Salas Auséns, J. A. (Coord.): Logros en femenino ..., op. cit., pp. 15-74 y Salas Auséns, J. A.: «Pero si ..., y si ..., por si ...», op. cit.

25. AHPH, leg. 941, Miguel de Mur, 1583. 
ENCARNA JARQUE MARTÍNEZ Y FRANCISCO JOSÉ ALFARO PÉREZ

HERENCIA, HONOR Y CONFLICTOS FAMILIARES EN EL ARAGÓN DEL SIGLO XVIII

\section{La Semilla de CaÍn}

Todas precauciones eran pocas y por mucho empeño que pusieran familia, costumbres y derecho en no dejar cabos sueltos, los conflictos estaban a la orden del día y sus motivos tan variopintos como los de nuestros días. En el seno del matrimonio, entre marido y mujer, la causa más frecuente solían ser los malos tratos que a veces denunciaba la esposa -haciendo caso omiso a los consejos de la iglesia o a las recomendaciones del Consejo de Castilla de dejar las diferencias familiares (los trapos sucios) dentro de la casa-, acudiendo a tribunales civiles o eclesiásticos para solicitar la separación. Entre padres e hijos - pero a falta de aquellos, también entre hermanos- eran las cuestiones de honor: padres o hermanos que querían impedir el matrimonio del hijo o de la hija, del hermano o de la hermana por considerarlo inconveniente, cuando no deshonroso para la familia. No obstante, las razones mas frecuentes fueron las de índole económico, si bien en ocasiones adoptaban formas más complejas al insertarse mimetizándose con otras causas o excusas.

En los conflictos conyugales el último paso era el recurso a los tribunales. Ante los primeros síntomas de desavenencia solía darse la mediación de los familiares más cercanos, con frecuencia los padres, pero también de otros parientes y vecinos. Si los problemas no se solucionaban por esta vía, las autoridades locales intervenían buscando forzar una concordia, incluso adoptando medidas coercitivas contra aquel a quien consideraban responsable de las desavenencias. Fracasados todos los intentos, quedaba el recurso a la justicia, siendo habitualmente la eclesiástica la elegida cómo árbitro ${ }^{26}$. Los malos tratos dados por los maridos eran los motivos más repetidos, pero no los únicos. Sirva como ejemplo habitual de los primeros la demanda de separación interpuesta ante el tribunal diocesano de Zaragoza en 1795, y ganada, por Teresa Puyol contra su marido Nicolás Torres. Nicolás y Teresa habían contraído matrimonio diez años antes en la localidad turolense de Segura de Baños. Los malos tratos de palabra y físicos comenzaron casi de inmediato. El marido la trataba públicamente «de tuna, bribona y que era de casta de

26. Vid. Ortega López, M.: «Protesta de las mujeres castellanas contra el orden patriarcal privado durante el siglo XVIII», op. cit., pp. 77-82, y «La práctica judicial en las causas matrimoniales de la sociedad española del siglo XviII", Espacio, tiempo y forma. Serie IV, Historia Moderna, 12, 1999, pp. 275-296; Lorenzo Pinar, Fco. J.: «Actitudes violentas en torno ...», cit. Para el caso de la de la archidiócesis zaragozana vid. Falcón Pérez, M. I.: «Procesos por causas matrimoniales en Zaragoza en la Baja Edad Media y Primer Renacimiento", Aragonia Sacra, 9, 1994, pp. 208-252, pp. 238-240; y Falcón Pérez, M. I., y Motis Dolader, M. A.: Procesos criminales en el Arzobispado de Zaragoza. Zaragoza, Diputación general de Aragón, 2000.

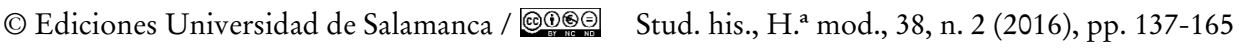


ENCARNA JARQUE MARTÍNEZ Y FRANCISCO JOSÉ ALFARO PÉREZ

HERENCIA, HONOR Y CONFLICTOS FAMILIARES EN EL ARAGÓN DEL SIGLO XVIII

vil» y, añadía la denunciante, «con otras razones que se omiten por la vergüenza que llevan consigo tales expresiones». Insultos y vejaciones iban acompañados de palizas, como la propinada el día de año nuevo de 1786. En la denuncia se detallaba lo sucedido: el marido le había pedido que fuera a comprar unas alpargatas sin dinero para pagarlas y el alpargatero no quiso fiarlas. De vuelta a casa Teresa estalló una discusión y Teresa sugirió a su esposo que fuera a pedírselas él. La propuesta enfureció a Nicolás que «sin mediar mas que esto, atropelló a mi parte pegándola a presencia de alguna persona y, marchada esta, cerró la puerta de la casa y comenzó de nuevo a pegarla y cansado de ello la arrastró de una pierna diciéndola vamos a la bodega, amenazando de muerte». Los gritos de Teresa atrajeron a un vecino que, tras encararse con el marido, la condujo a su casa, «expresando que temía no la matase, y quería preservarla de semejante bruto» y después la llevó al domicilio de sus padres, donde permaneció cuatro meses. Los intentos de la familia por reconciliar al matrimonio no dieron resultado y Teresa solo accedió a volver después de que Nicolás diera palabra de enmienda al párroco y al alcalde del pueblo, quienes le apercibieron con ser castigado si volvía a maltratarla. El arrepentimiento duró muy poco y pronto volvieron los malos tratos, llegando a golpearle en una ocasión con unas tenazas en la cabeza, dándole palizas cuando estaba embarazada. Teresa volvió a refugiarse en casa de sus padres que, como la vez primera, acabaron por «convencerla» para volver con su marido. Tiempo más tarde, en 1793, la pareja se trasladó a Zaragoza, donde continuaron unos malos tratos ratificados por varios testigos, entre ellos una criada que sirvió dos meses en el domicilio de la pareja y que atestiguó haber visto maltratarla a «golpes, bofetadas y malos tratamientos», amenazarla con una escopeta, golpearla y arrastrarla por el suelo al grito de «que no había de parar hasta cortar la cabeza de su mujer». Incapaz de soportar por más tiempo la situación y temiendo por su vida, Teresa pidió amparo al tribunal eclesiástico, solicitando aprobara su separación, como así fue ${ }^{27}$.

En el caso de Joaquín Gayán y Miguela Díaz Salvador, de Cariñena, la denuncia presentada el año 1763 en el arzobispado de Zaragoza por Miguela añadía a los malos tratos que le daba su marido la dilapidación del patrimonio familiar por su afición al juego. Gayán, miembro a la élite local, se había casado con Miguela, joven acomodada de la vecina localidad de Paniza, en un matrimonio concertado entre iguales. Miguela tenía un hermano eclesiástico, que disfrutaba de un beneficio en la rica parroquia de Cariñena. En su denuncia relataba los malos tratos:

27. Archivo Diocesano de Zaragoza [en adelante ADZ] Teresa Puyol pide la separación de Nicolás Torres, Zaragoza, 1795. Los malos tratos denunciados en este proceso son similares a los que se recogen en múltiples casos llevados ante las instancias eclesiásticas, vid. PINAR, F. J.: «Actitudes violentas ...», op. cit., pp. 179-180.

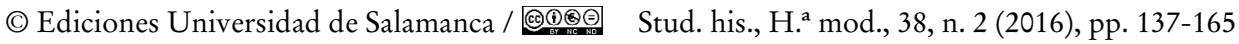


ENCARNA JARQUE MARTÍNEZ Y FRANCISCO JOSÉ ALFARO PÉREZ

HERENCIA, HONOR Y CONFLICTOS FAMILIARES EN EL ARAGÓN DEL SIGLO XVIII

golpeada en varias ocasiones, una vez fue arrojada por las escaleras de su casa a consecuencia de lo cual abortó. Su testimonio daba cuenta de la afición de su marido al juego, lo que le había llevado a enajenar parte de su patrimonio, dando detalles de cómo las dificultades económicas habían llegado incluso a la mesa. Uno de los testigos, que había servido en la casa durante dos años, dijo haber visto que le había pegado en varias ocasiones y le había amenazado con tirarla a un pozo y con tirarle una silla; añadió que en una ocasión debió acudir el hermano cura de la mujer y en medio de una violenta discusión Gayán encañonó a los dos con una escopeta. Otro testigo dijo saber que Gayán había vendido 300 ovejas y dos fincas, y que su mujer le recriminaba constantemente su afición al juego, motivo principal de las discusiones. La decisión del tribunal eclesiástico fue conminar al marido a mantener el respeto a su mujer e instar a esta a continuar en el domicilio conyugal ${ }^{28}$.

Malos tratos fueron también las razones en las que Joaquina Pladeball, hija de un acomodado platero zaragozano, basaba su demanda de separación del también platero Pascual Cabello, y a ello añadía la de abandono del hogar. El marido, desde el primer día de su matrimonio se jactaba de que «se había casado por la fuerza y que si había condescendido era por los dineros de su suegro, y por la esperanza de su empleo, pero no por la mujer, que no la había de tocar, pues para eso había putas». Según Joaquina, su marido ni siquiera había llegado a cosumar el matrimonio, y así lo exponía su procurador «en el tiempo que estuvo con ella aparentó tener un matrimonio de calidad, pero no es así ya que dice que no quiere verse en la precisión de tener un hijo con ella... así que Joaquina se encuentra intacta». Pascual prácticamente no aparecía por la casa y cuando lo hacía maltrataba a su esposa; pasaba las noches fuera y tan apenas acudía al taller de su suegro. Todo ello llevó a su mujer a pedir la separación a las autoridades eclesiásticas. La sentencia le permitía volver a casa de sus padres ${ }^{29}$.

Aun siendo mucho más frecuentes los casos de denuncias de separación interpuestos por mujeres, también los hay presentados por el marido. De estos últimos, una causa recurrente es la de esgrimir que ellas no hubieran llegado vírgenes y puras al matrimonio, razón aducida por el mercader Juan Uturre, que pedía se le concediera la separación de su esposa, la navarra Joaquina Garroberea. Sostenía que no había llegado virgen al matrimonio y que a los tres meses de estar casados ella había dado luz a una niña, fruto de relaciones con otro hombre ${ }^{30}$.

28. ADZ, 1763, Joaquín Gayán y Miguela Díaz Salvador, Cariñena.

29. ADZ, 1803, Joaquina Pladeball, contra su marido Pascual Cabello, platero, Zaragoza.

30. ADZ, 1745, Juan de Uturre, mercader, contra Joaquina Garroberea, Longares.

(C) Ediciones Universidad de Salamanca / ®@ Stud. his., H. ${ }^{a}$ mod., 38, n. 2 (2016), pp. 137-165 
ENCARNA JARQUE MARTÍNEZ Y FRANCISCO JOSÉ ALFARO PÉREZ

HERENCIA, HONOR Y CONFLICTOS FAMILIARES EN EL ARAGÓN DEL SIGLO XVIII

Hubo recursos a los tribunales en los que el objeto de la demanda no era un conflicto matrimonial, sino el hecho de que la pareja viviera separada, situación que solía estar motivada por antiguos conflictos, pero no siempre. En estos casos la acusación ante los tribunales solía provenir de terceros, escandalizados por el hecho y por sus repercusiones entre el vecindario de las localidades en que esto ocurría. Fue el motivo, por ejemplo, por el que fueron denunciados los vecinos de Daroca Miguel Mozota y su esposa Catalina Benito, en Daroca, a quienes desde el arzobispado se instó, bajo pena de excomunión, a hacer «vida conyugal y maridable habitando en la misma casa y compañía» ${ }^{31}$. Similar ruego expresó el párroco de Villafeliche al matrimonio de José Santos y Francisca Asensio, o el de Segura de Baños a Joaquín Latorre y su esposa María Teresa Anadón ${ }^{32}$. En este último caso, antes que el párroco ya habían intentando la reconciliación las autoridades judiciales y un fraile que había predicado en la última cuaresma, intentando convencer a la mujer "para reducirla a que viva con su marido como Dios manda», pero todo había sido en vano, ante la obstinación de la mujer que amenazaba incluso con el suicidio si se le obligaba a reanudar la vida conyugal, «afirmando que primero hará un desatino, aunque se la lleven los demonios»33.

La defensa de la honra de la familia aparece también como fuente de conflicto, en este caso entre padres e hijos o, a falta de aquellos, entre hermanos. Normalmente se trataba de enlaces rechazados por ser considerados desiguales social o económicamente. Este tipo de conflictos pudo verse favorecido por la Real Pragmática dictada por Carlos III en 1776, por la que se ordenaba que todo matrimonio contara con el consentimiento paterno o, a falta de estos, de los abuelos o de familiares más cercanos ${ }^{34}$. La falta de consentimiento podía llevar a la pérdida automática de los derechos sucesorios ${ }^{35}$. La aprobación familiar se requería para hombres y mujeres y quienes recurrían a los tribunales podían ser el padre o, en su ausencia, quien hiciera las veces de cabeza de familia, pero también los

31. ADZ, 1795, 1795, El fiscal contra los vecinos de Daroca Miguel Mozota y su mujer Catalina Benito.

32. ADZ, 1789, El rector de Villafeliche contra José Santos y Francisca Asensio, vecinos de Villafeliche; 1799, el rector de Segura de Baños contra Joaquín Latorre y María Teresa Anadón.

33. Ibidem.

34. Sobre la incidencia de esta orden véanse los trabajos de Baldellou Monclús, D.: «El honor de los padres y la libertad de los hijos: La aplicación del veto paterno a los matrimonios transgresores en la España preliberal» y de RAmiro MoyA, Fco.: «El matrimonio y sus conflictos a finales de la Edad Moderna. Una historia con mujeres», ambos recogidos en Alfaro Pérez, F. J. (Coord.): Familias Rotas. Zaragoza, 2014, pp. 47-99 y 101-167, respectivamente.

35. Novísima Recopilación, libro X, Título II, De los esponsales y matrimonios; y sus dispensas Ley IX «Consentimiento paterno para la contracción de esponsales y matrimonio por los hijos de familia», pp. 11-13.

(C) Ediciones Universidad de Salamanca / @@@ Stud. his., H. ${ }^{\mathrm{a}}$ mod., 38, n. 2 (2016), pp. 137-165 
ENCARNA JARQUE MARTÍNEZ Y FRANCISCO JOSÉ ALFARO PÉREZ

HERENCIA, HONOR Y CONFLICTOS FAMILIARES EN EL ARAGÓN DEL SIGLO XVIII

pretendientes frustrados. Para unos el objetivo era impedir un matrimonio pactado y para otros la pervivencia de un orden socioeconómico.

La causística fue casi tan variada como sus protagonistas. De conflicto «común» podría tacharse el de un padre, como José Losmoros, opuesto al enlace de su hijo, de su mismo nombre, con una joven de menor poder económico y de familia peor considerada, como la de Joaquina Coto, en este caso en Sariñena (Huesca). El motivo alegado por el padre era que el abuelo de la novia había sido cortante, profesión considerada infamante. Ante el anuncio de las pertinentes amonestaciones prenupciales, Jose Losmoros, mayor, acudió al tribunal eclesiástico y civiles de Huesca, que ordenó al párroco paralizar los trámites de la boda en tanto la justicia ordinaria, a la que también recurrió el padre, dictara sentencia. Los argumentos aducidos eran claros: «es nieta de cortantes y en su virtud padece esta nota de tanta gravedad, (...) con la nota ofensiva y tan gravemente perjudicial a la estimación, limpieza y honradez de dicha mi familia y no siendo justo que por la inconsideración de dicho Joseph Losmoros, mi hijo, se atropelle el honor de mi familia y honrados parientes de ella». Finalmente, el padre del novio se salió con la suya impidiendo el enlace ${ }^{36}$. Sin embargo, la casuística, como se ha indicado, es muy variopinta. Otra perspectiva de pleitos similares puede observarse en las demandas de la fragatina Francisca Sarda, soltera, y de la viuda Teresa Iguacen, de Bolea (Huesca) cuando solicitaron a los tribunales permiso para casarse con respectivos cortantes contrariando las intenciones del padre de la primera y de la madre de la segunda que se negaban a dar el consentimiento. En ambos casos la sentencia accedió a las pretensiones de las demandantes ${ }^{37}$.

La defensa de la honra familiar también estaba detrás de pleitos entre hermanos, como el surgido por la negativa de Miguel Portolés, labrador de Torrecilla de Alcañiz, a dar el visto bueno al matrimonio proyectado por su hermano León a quien los tribunales autorizaron el enlace ${ }^{38}$. Similar fue el caso de Antonio Beltrán, quien pedía a la justicia que obligara su hermano Clemente a darle consentimiento para casarse con Eugenia Beltrán, todos de Villanueva de Huerva (Zaragoza) $)^{39}$. Más raros son los ejemplos de oposición de una hermana al matrimonio de un hermano, pero existieron como acredita el pleito del zaragozano Tomás Pueyo contra su hermana Luisa, pidiendo a los tribunales que la obligaran a aprobar su enlace con María José Panyvino ${ }^{40}$. En cambio, son frecuentes las

36. AHPZ, Pleitos civiles, caja 1.094-4, año 1778.

37. Idem, cajas 4831-4, año 1794 y 2589-1, año 1780.

38. Idem, caja 1.703-10, año 1803.

39. Idem, caja 3.608-1, año 1798.

40. Idem, caja 2.363-5, año 1800.

(C) Ediciones Universidad de Salamanca / @@@ Stud. his., H. ${ }^{\mathrm{a}}$ mod., 38, n. 2 (2016), pp. 137-165 
ENCARNA JARQUE MARTÍNEZ Y FRANCISCO JOSÉ ALFARO PÉREZ

HERENCIA, HONOR Y CONFLICTOS FAMILIARES EN EL ARAGÓN DEL SIGLO XVIII

denuncias presentadas por mujeres ante la resistencia de sus padres o hermanos a darles el imprescindible visto bueno. Sería el caso del expediente instado por Joaquina Lagarda sobre el consentimiento que solicitaba de su hermano Antonio para el matrimonio que pretendía contraer don Martín Maza, soltero natural de Uncastillo (Zaragoza) $)^{41}$. En estas situaciones en que la familia se oponía al matrimonio, la legislación aragonesa ofrecía una alternativa al que deseaba contraerlo, la manifestación, mecanismo por el que los tribunales daban protección a la persona que se acogía a la misma, separándoles de los denunciados y custodiándolos en sus propias dependencias o señalando algún domicilio que les pareciera seguro hasta que la reclamación fuera resuelta judicialmente ${ }^{42}$. Se evitaba así cualquier violencia que pudiera ejercerse contra la persona manifestada. El caso de Sebastiana Perales y Ventura, hija del barón de la Torre, ilustra esta situación: Sebastiana, de veinte años, se había dado palabra de matrimonio con Valentín Sancho, infanzón de la villa de la Almunia de doña Godina (Zaragoza). Sus padres, su hermana Mariana y el marido de esta, el caballero valenciano Francisco Perpiñán, se oponían radicalmente, hasta el punto de impedirle salir de casa. El motivo era la opinión que tenían del novio: «persona desarrahigada, procura atraer la voluntad de $\mathrm{D}^{\mathrm{a}}$ Sebastiana para adquirir para este término un patrimonio opulento». Decidida a casarse y ante la imposibilidad de vencer la resistencia de los suyos, Sebastiana se manifestó ante la justicia de la Almunia, solicitando se le diera aposento en «casa o paraje onesto según mis circunstancias y disposiciones de esta causa y tribunal, y observe lo demás dispuesto por fuero y leyes del Reyno». La decisión del juez, firmada el 7 de octubre de 1794, fue ordenar el traslado de Sebastiana al domicilio del infanzón Sebastián Labiaga. La familia de Sebastiana se negó a cumplir la decisión del tribunal, reteniéndola en casa. Pero esa misma noche, con ayuda de su novio, Sebastiana lograba escapar. Según algunos testigos, en torno a la medianoche su novio Valentín comenzó a tirar piedras al balcón del cuarto de Sebastiana. Esta dijo a sus criados que se asomaba para calmarlo, pero desde la calle el novio y algunos otros que le acompañaban colocaron «una escala (en) la casa por un balcón, desde el qual un amigo de D. Valentín Sancho ayudó a $\mathrm{D}^{a}$ Sebastiana a vajar por la escala, que para ello había puesto, diciendo a la criada el que subió que si hablaba la mataría, y habiéndola vajado de este modo se la llebó el alcalde, auxiliado de criados de D. Domingo Sancho, tío carnal de D. Valentín». Sebastiana

41. Idem, caja 2.057-2, año 1787.

42. Sobre la pervivencia del privilegio de Manifestación tras los decretos de Nueva Planta, vid. BAldellou Monclús, D.: «La sombra de los fueros es alargada. El proceso de manifestación tras los decretos de Nueva Planta», en Colás Latorre, G. (Coord.): Estudios sobre la sociedad aragonesa en la Edad Moderna. Zaragoza, Mira Editores, 2015, pp. 181-230.

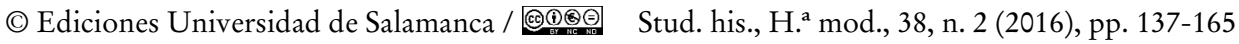


ENCARNA JARQUE MARTÍNEZ Y FRANCISCO JOSÉ ALFARO PÉREZ

HERENCIA, HONOR Y CONFLICTOS FAMILIARES EN EL ARAGÓN DEL SIGLO XVIII

sería trasladada unos días más tarde a Zaragoza a una casa de manifestados y en este caso la justicia le daría la razón y el 22 de diciembre de aquel mismo año contraía matrimonio legítimo con Valentín ${ }^{43}$.

Pero los conflictos más frecuentes, a veces bajo la apariencia de defensa de la honra, muchas otras abiertamente, escondían móviles económicos: descontentos por el reparto de herencias, clausulas testamentarias incumplidas, deudas insatisfechas, alzamiento de bienes, disposición irregular de recursos, apropiaciones indebidas, diferencias a la hora de repartir el patrimonio paterno, dotes insuficientes, testamentos inválidos, etc. En los dos centenares de pleitos entre hermanos que, juzgados en tribunales inferiores, fueron apelados a la Audiencia de Aragón, encontramos conflictos de todo tipo, en todos los sectores de la sociedad y distribuidos a lo largo y ancho del territorio. Como denunciantes o denunciados, nobles que se disputaban la posesión de un título con sus rentas, militares, artesanos, comerciantes, abogados, escribanos, estudiantes, ganaderos, labradores, curas, frailes, monjas... están presentes en los pleitos, prácticamente todos ellos movidos por un denominador común, la disputa por la propiedad sobre los recursos familiares. Pero bajo este denominador común encontramos una casuística muy rica en matices que podría esquematizarse en:

- Casos de abusos de hermanos adultos sobre menores. Como el de los hermanos Bernardo, Pedro, José y Ana Labad que se repartieron una casa y un corral en Sádaba (Zaragoza), ignorando los derechos que también tenía sobre los mismos Ángela de 7 años de edad. Aquí fue el tutor de la niña, Patricio Alastruey, quien llevaría el caso a los tribunales locales, que fallaron en su contra al presentar su recurso con defectos de forma y fuera de plazo $^{44}$.

- Situaciones en las que un hermano aprovechaba su mejor conocimiento del verdadero valor de los bienes familiares en el momento de su reparto. Es eso lo que ocurrió en la partición de la herencia de Joaquín García y Francisca San Juan entre sus hijos Pedro y María Manuela. A pesar del acuerdo firmado ante notario en 1762, una de cuyas clausulas contemplaba la renuncia expresa acudir a los tribunales - «Dichas partes prometieron y se obligaron haber y tener por firme la presente escritura sin poder contravenir a ella en tiempo ni manera alguna»-, un año después Pedro acudía a la justicia de Alcorisa, aduciendo que el reparto no había sido ecuánime y que hermana y cuñado se habían quedado la mejor parte, razón por la que solicitaba su modificación.

43. AHPZ, Pleitos Civiles, caja 1.571-1, año 1794.

44. Idem, caja 1.367-7, año 1798.

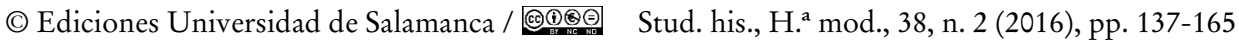


ENCARNA JARQUE MARTÍNEZ Y FRANCISCO JOSÉ ALFARO PÉREZ

HERENCIA, HONOR Y CONFLICTOS FAMILIARES EN EL ARAGÓN DEL SIGLO XVIII

Basaba su petición en la mala fe de la parte contraria y la ignorancia propia. Aducía que había pasado su juventud dedicado a estudiar, barajando con su familia su dedicación a la iglesia y tanteado su ingreso en un convento de la localidad, motivo por el que desconocía el valor del patrimonio paterno. La verosimilitud de sus argumentos, bien fundados, es total. Pedro tenía razón al sentirse engañado, pero los tribunales no accedieron a su demanda, obligados como estaban a dar prioridad a las clausulas de la escritura de partición ${ }^{45}$.

- Entrega insuficiente de alimentos. Ejemplifica este extremo lo ocurrido a Ventura Clemente, de 68 años y soltera, que en 1776 iniciaba un pleito contra su hermano José, acusándole de interrumpir la entrega de los 3 cahices de trigo y 4 libras anuales a que estaba obligado por el testamento de su padre, que le había nombrado heredero con esa condición. La situación de Ventura al acudir a los tribunales debía ser muy apurada, tenida como «señora de calidad he hija de padres nobles», estaba viviendo de limosna. Los tribunales le dieron la razón, ordenando a su hermano a satisfacer los atrasos y seguir pagándole lo estipulado en el testamento paterno y condenándole al pago de las costas judiciales ${ }^{46}$. Parecida fue la reclamación de José Paricio contra su hermano Antonio. Le reclamaba la entrega de dos reales de plata diarios, por los cuatro meses que se había mantenido fuera de su casa, la mitad de la cosecha de oliva y «habitación cómoda y proporcionada en las casas de sus difuntos padres». Como en el caso precedente, José había llegado a una situación de penuria extrema, «en tanto grado que para su manutención se ha visto y ve precisado a pedir limosna». La sentencia de Alcañiz, que obligaba a Antonio a cumplir lo previsto en el testamento sería apelada por este a la Audiencia, que sin dilación la confirmaría ${ }^{47}$.

- Reclamaciones por incumplimiento de pago de lo estipulado en el testamento. Como en el caso de los pleitos por alimentos, las sentencias de la Audiencia ante este tipo de conflictos iban siempre en la misma línea: obligar al estricto respeto a las disposiciones testamentarias, en ocasiones revocando lo dispuesto por los jueces locales. La demanda de Antonia Villanova, vecina de Fraga, contra su hermano Gregorio, sobre recobro de maravedís es un buen ejemplo de ello. Los Villanova eran seis hermanos: José, Basilio y Melchor, presbíteros, Gregorio, militar, Clara y Antonia. Los padres, ya fallecidos, habían dejado heredero fideicomisario a su hijo

45. AHPZ, Pleitos civiles, caja 4.641-6, año 1763.

46. AHPZ, Pleitos civiles, caja 3.843-2, año 1776.

47. AHPZ, Pleitos civiles, caja 47-4, año 1775.

(C) Ediciones Universidad de Salamanca / ®@ Stud. his., H. ${ }^{a}$ mod., 38, n. 2 (2016), pp. 137-165 
ENCARNA JARQUE MARTÍNEZ Y FRANCISCO JOSÉ ALFARO PÉREZ

HERENCIA, HONOR Y CONFLICTOS FAMILIARES EN EL ARAGÓN DEL SIGLO XVIII

José, «con la facultad absoluta de poder disponer y distribuir todos los bienes y herencia de aquel en los demás hijos e hijas suyos... dando a qual mas a qual menos a qual todo y a qual nada». Siguiendo la costumbre de la zona, la decisión de José, en su testamento fechado en 1763, fue nombrar como heredero universal a su hermano Gregorio, pero con determinadas condiciones: dar 880 libras a su hermana Antonia, 720 a Clara, por entonces soltera, y 200 libras a cada uno de los dos hermanos curas, Basilio y Melchor. Tres años después de la firma del testamento, Antonia, viuda y en una difícil situación económica, que le llevó a solicitar y obtener justicia gratuita, acudía a los tribunales reclamando a Gregorio su parte de la herencia. A pesar de que el asunto no ofrecía duda alguna, el proceso se dilató muchos meses por las tácticas dilatorias de Gregorio, intentando primero acogerse a la justicia militar, en su condición de tal; argumentando a continuación que para poder disponer de dinero en efectivo tenía que enajenar alguna de sus propiedades y que puestas a la venta no encontraba comprador; ofreciendo a su hermana darle una finca cuyo valor estimaba equivalente, propuesta que Antonia rechazó por tratarse de una propiedad sobre la que pesaban muchas cargas censales; finalmente, ya en mayo de 1768, pidiendo a los tribunales le permitieran posponer el pago hasta el mes de setiembre «levantada que sea la cosecha con cuyo producto y otros arbitrios que en el interim podrá proporcionarse pueda satisfacer evitando la total ruina de su casa». Posiblemente obligada por sus apuros económicos Antonia se había ido oponiendo a todas estas propuestas. Finalmente en los últimos días de julio y ante la amenaza de embargo, Gregorio hizo entrega a su hermana de las cantidades demandadas ${ }^{48}$.

- Irregular pago de la dote. En las familias en que se nombraba heredero a uno de los hijos era habitual encomendarle el cuidado de sus hermanos solteros mientras siguieran viviendo juntos en la casa familiar y proporcionarles una dote cuando se casaran. La fórmula empleada tanto en las capitulaciones matrimoniales, en las que los padres de uno de los contrayentes le reservaban la herencia del patrimonio familiar, como en los testamentos era con el cargo «de alimentar, vestir y calzar a los demás sus hermanos y dotarles al poder y aber de la casa quando tomaran estado «. El término «al poder y aber de la casa» era impreciso y esta imprecisión abría la puerta a los desheredados que podían considerarse injustamente tratados con la dote que se les asignaba. Fue el caso del médico Andrés Sanz, que presentó

48. Idem, caja 4.570-6, año 1766.

(C) Ediciones Universidad de Salamanca / @@ Stud. his., H. ${ }^{a}$ mod., 38, n. 2 (2016), pp. 137-165 
ENCARNA JARQUE MARTÍNEZ Y FRANCISCO JOSÉ ALFARO PÉREZ

HERENCIA, HONOR Y CONFLICTOS FAMILIARES EN EL ARAGÓN DEL SIGLO XVIII

una demanda ante los tribunales contra su hermano Antón, un labrador de Plasencia del Monte, pequeña localidad oscense. Antón, heredero del patromino familiar, había ido dotando a sus otros hermanos a medida que se casaban. Sus hermanas Ana y Catalina fueron dotadas cada una con 100 libras; a su otro hermano, Ramón, le asignó 350 libras al casarse con una doncella de la próxima localidad de Los Corrales y más adelante, seguro de no tener descendencia, le nombró heredero. Andrés se sintió preterido y llevó el asunto a la justicia, argumentando que se había casado hacía ya varios años sin lograr que, a pesar de su insistencia, su hermano le asignara dote alguna. Reclamaba una cantidad similar a la señalada a Ramón. Antón se defendió ante el tribunal esgrimiendo los elevados gastos que supusieron a la casa los estudios de Andrés, su título de médico y los medios de que se le proveyó para que pudiera ejercer la profesión, con un montante muy superior a las dotes entregadas a los demás. Andrés, por su parte, exponía que todo ello había sido sufragado por un tío, eclesiástico. Verdades a medias por cada parte, testigos de uno y otro adveraban sus argumentos y el tribunal falló en sentencia de 27 de julio de 1807, dando la razón a Andrés, pero rebajando la dote a entregar por Antón a 120 libras $^{49}$.

- Alzamiento de bienes. Esta situación no era nada rara en los casos en que era solo uno de los hermanos el que convivía con los padres en el momento de la muerte de estos. Resultaba fácil caer en la tentación de ocultar parte de los bienes muebles antes de proceder a su reparto y esto es lo que denunció Joaquín Manero ante la muerte de su cuñado Antonio Gómez, llevando a los tribunales a la viuda, su hermana Sebastiana, acusándola de «haver ocultado la referida Sebastiana Manero diferentes bienes que deven partirse y dividirse ${ }^{50}$. Parecidas las razones que llevaron al turolense Miguel Juan Martín a pleitear contra su hermano Juan Antonio, disconforme ante el reparto de los bienes inventariados y descritos por las muertes intestadas de sus padres ${ }^{51}$.

- Tasación de deudas. El origen del conflicto no siempre estaba originado por problemas derivados de las herencias. La distinta estimación del volumen de deudas contraídas por una de las partes con la otra podía suponer el fin de unas relaciones cordiales. El pleito interpuesto el año 1778 en los tribunales por Juan José Biñerta, administrador de la Real Salinas de Arcos, contra su hermana Juana, entonces vecina de Albarracín, es un perfecto

49. Idem, caja 95-3, año 1806.

50. Idem, caja 4.598-1, año 1813.

51. Idem, caja 99-2, año 1778.

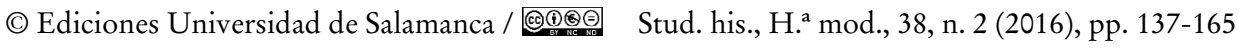


ENCARNA JARQUE MARTÍNEZ Y FRANCISCO JOSÉ ALFARO PÉREZ

HERENCIA, HONOR Y CONFLICTOS FAMILIARES EN EL ARAGÓN DEL SIGLO XVIII

ejemplo de este tipo de disensiones. Durante varios años Biñerta y su cuñado José Guerrero, esposo de Juana, habían llevado juntos entre otros negocios la compra de lanas en la Sierra de Albarracín (Teruel), que luego vendían a comerciantes franceses en Valencia. Compaginaban esta actividad con otros negocios que iban desde la compraventa de cereales hasta el alquiler de la ferrería de Gea de Albarracín. En un reparto de funciones, era Biñerta quien desde Teruel llevaba las cuentas de la sociedad, en tanto que su cuñado se preocupaba del día a día de los negocios. La muerte de Guerrero en 1771 supuso el fin la sociedad. Su viuda encargaba en distintas cartas remitidas a José Garcés, familiar de su marido, que pasara las cuentas, encareciéndole a hacerlo con la mayor equidad a fin de que, decía, «que mediante el levantamiento que VM. y Sr. Sevasthián harán de ellas, podamos vivir mi hermano y yo con la mayor claridad, que esto ha sido y es lo que procede entre hermanos». La buena disposición de la viuda a un amigable acuerdo con su hermano se iba desvaneciendo, sobre todo a raíz de su segundo matrimonio con Basilio Andreu, regidor de la ciudad de Albarracín, quien puso todo tipo de obstáculos al acuerdo, poniendo en duda las detalladas cuentas que le presentaba Juan José Biñerta, a pesar de que venían avaladas por Juan Garcés, persona en quien había confiado su esposa. Valiéndose de su condición de regidor, Andreu logró trasladar las pesquisas a los tribunales de Albarracín, a la vez que cambió la buena disposición que inicialmente había demostrado la esposa hacia su hermano Juan José. En efecto, el 13 de enero de 1778, Juana Biñerta hacía una declaración ante el escribano del tribunal en la que exponía que, afligida por la muerte de su marido y abrumada por la serie de asuntos relacionados con sus actividades comerciales a los que debía dar respuesta, puso todo en manos de su hermano, quien le ocultó algunos extremos. Preguntada por las cartas en las que encomendaba a su pariente José Garcés arreglar las cuentas pendientes, afirmó «que ambas dos las firmó en blanco, cuias firmas reconoce ser suias y escritas de su propio puño y letra, pero no hace memoria ni se acuerda haberlas dictado, ni tan sólo una palabra y si se escribieron a las repetidas instancias del dicho su hermano, ni menos haber comprometido las pretensiones de este por estar bien asegurada no deberle las cantidades que se figuran $»^{52}$. La mano de su marido Basilio estaba sin duda en este cambio de actitud de Juana hacia su hermano, algo habitual en los procesos de ruptura familiar recogidos en la cultura popular ${ }^{53}$.

52. Idem, caja 4.008-4 año 1778.

53. Así lo recoge el título del artículo de BorXados, R., «"Cuñados no son parientes sino

(C) Ediciones Universidad de Salamanca / @@ Stud. his., H. ${ }^{a}$ mod., 38, n. 2 (2016), pp. 137-165 
ENCARNA JARQUE MARTÍNEZ Y FRANCISCO JOSÉ ALFARO PÉREZ

HERENCIA, HONOR Y CONFLICTOS FAMILIARES EN EL ARAGÓN DEL SIGLO XVIII

- Conflictos sobrevenidos tiempo atrás. El comportamiento de alguno de los hijos en vida de sus padres era, a veces, preludio seguro de conflictos a la muerte de éstos. Los afectos solían tener recompensa y los desafectos sanción. Era frecuente en las últimas disposiciones reservar en forma de gracia especial una parte del patrimonio e incluso dejar la herencia al hija o hija que había cuidado de sus progenitores en los últimos años de su vida y también habitual el descontento de los otros hermanos, considerando injusta la decisión paterna. El testamento del viudo Juan Martín, vecino de Daroca (Zaragoza) y sus consecuencias son buen ejemplo perfecto de ello. Juan tenía dejaba cinco hijos: Vicente, Joaquín, Lucía, Eusebia y María. Vicente, el mayor de los varones, tras su matrimonio había continuado viviendo durante algún tiempo con su esposa en el domicilio paterno. Al abandonarlo, fue su hermana Lucía, viuda y madre de dos hijos pequeños, quien ocupó su lugar, atendiéndo al padre hasta el fin de sus días. Era lo que este reconocía expresamente en su testamento, en el que, además de beneficiarla con gracias especiales como a otros hermanos, la nombraba heredera de lo que quedara por repartir «en atención a los muchos y señalados beneficios que le devo y al particular cuidado y esmero con que me ha asistido en mis achaques y enfermedad». No contento con la decisión paterna, Vicente intentó impugnar el testamento, aduciendo ciertos defectos formales en el propio testamento, pero su protesta fue vana. El problema estaba en una negligencia del escribano encargado de incluir el documento en el protocolo correspondiente, razón por la que la demanda fue desestimada ${ }^{54}$. En este sentido no solo el afecto, sino también el desafecto de los padres hacia uno de sus hijos anticipaba inevitables conflictos. Un testamento como el de Pablo Franco, hecho en Las Parras (Teruel) en 1742 a la fuerza tenía que llevar a sus hijos a enfrentarse en los tribunales. El documento, cerrado, había quedado bajo la custodia del notario del lugar, que procedió a su apertura a la muerte del testador. En él dejaba heredera a su hija Clara con la que convivía y a la que, al igual que a otra hija, Antonia, había dado una elevada dote para su matrimonio. La condición que le imponía era el cuidado de un tercer hijo, José, aquejado de graves problemas físicos. El cuarto hijo era el presbítero Francisco, beneficiado en la parroquia de Castelserás (Teruel). Sus padres, en un testamento mancomunado dictado en 1731 le habían dejado en usufructo de por vida varias heredades, que se

accidentes”. Conflictos familiares en torno a la herencia de Cochangasta. (La Rioja, siglo XviII)», Anuario del CEH, 1, 2001, pp. 39-61.

54. AHPZ, Pleitos Civiles, caja 763-2, año 1818.

(C) Ediciones Universidad de Salamanca / ®@ Stud. his., H. ${ }^{a}$ mod., 38, n. 2 (2016), pp. 137-165 
ENCARNA JARQUE MARTÍNEZ Y FRANCISCO JOSÉ ALFARO PÉREZ

HERENCIA, HONOR Y CONFLICTOS FAMILIARES EN EL ARAGÓN DEL SIGLO XVIII

venían a añadir a la renta que ya gozaba de dos beneficios, uno en la iglesia de Castelserás y otro en la de Las Parras. Habían pasado once años desde su anterior disposición de bienes y entre tanto se había producido un desencuentro total entre el cura y su padre que ahora recordaba las atenciones que le había dispensado: «lo crié con toda decencia y estimación ... sin que jamás le faltara cosa alguna; lo presenté y puse en posesión de un beneficio pingüe de la casa que fue fundación de los bienes de mis abuelos; ... su madre y yo le izimos donación de tres posesiones ... para que sin poderlas vender las usufructuara durante su vida», escribía de su puño y letra. Pero el hijo no correspondió de la misma manera, tal como añadía a continuación: «pero no a sido atento y obediente como los hermanos suios lo an sido, porque tal a sido su proceder que aun antes de ordenarse me urtava de casa quanto podía alcanzar, abriéndome las arcas en diferentes ocasiones, tomándose lo que le parecía y me urtó muchos de los diges de oro y plata y porción de los vestidos de su madre, los malvendía, malgastando lo que sacaba de ellos con otros suxetos estraños de su genio; y es voz común que aun después de sacerdote, me abrió con una segur de noche la puerta de mi escribanía y me urtó lo que le pareció y encontró de valor demás de treinta pesos». Añadía otros detalles como la necesidad de cubrirle cuantiosas deudas generadas por su estilo de vida. Todo ello era motivo más que suficiente para limitar su herencia a la obligada legítima, cinco sueldos en dinero y otros cinco en tierra blanca. Le perdonaba las cantidades que le había dejado, pero con la condición de que dejara tranquilas a sus hermanas a las que el cura había amenazado «con que después de mis días las a de confundir a pleitos». En caso de no hacerlo, le mandaba que «so pena de pecado mortal según la ley de Dios, restituia todo quanto desde que tuvo uso de razón urtó y defraudó de los bienes de mi casa». De nada valieron las cautelas de Pablo Franco. Pocos días después de su muerte, su hijo el cura Francisco comenzaba un largo pleito con sus hermanas en el que cuestiones de forma, esta vez sí, le servirían para lograr de los tribunales la nulidad del testamento paterno, lo que le permitiría hacerse con una buena parte de la fortuna familiar ${ }^{55}$.

- Disputas por títulos de nobleza, con sus anejas rentas señoriales, eran otras de las razones que podían estar detrás de conflictos entre hermanos. La ley y la costumbre habían acotado el terreno para evitar pleitos de esta índole. Como norma general, era el varón primogénito quien heredaba el título y los recursos económicos que lo acompañaban y en la línea sucesoria siempre

55. Idem, caja 823-1, año 1757.

(C) Ediciones Universidad de Salamanca / @@ Stud. his., H. ${ }^{a}$ mod., 38, n. 2 (2016), pp. 137-165 
ENCARNA JARQUE MARTÍNEZ Y FRANCISCO JOSÉ ALFARO PÉREZ

HERENCIA, HONOR Y CONFLICTOS FAMILIARES EN EL ARAGÓN DEL SIGLO XVIII

prevalecía el varón sobre la mujer. Ello no obstante, las disensiones menudeaban y los tribunales tenían que enfrentarse a complejísimos y duraderos pleitos. Linajes truncados por falta de descendencia solían ser el desencadenante de las disensiones. Era la oportunidad de los segundones y, en su caso, de las mujeres de hacerse con un título y unas rentas hasta entonces poseídas por otro familiar. Fue la oportunidad para María Teresa Ximénez de Urrea de acceder al señorío de Berbedel en el que, además del título, se ventilaba la titularidad de una torre en el propio lugar, una casa, un huerto y una finca en Épila, dos censales de mil libras de propiedad dos molinos harineros y un molino batanero en Calatayud. Pleiteaba con su hermana Joaquina, marquesa de Hermosilla, casada y sin hijos, porque juzgaba que, según lo previsto en el testamento del padre de ambas, Francisco Ximénez de Urrea, el señorío debía recaer en su hijo, el militar Fernando Monserrat Ximénez de Urrea, teniente de las reales guardias en Méjico $^{56}$.

\section{A MODO DE CONCLUSIÓN}

Recapitulando, a través de la casuística observada puede llegarse a la conclusión de que la conflictividad familiar en el reino de Aragón del siglo xviı y principios del XIX estuvo causada por múltiples motivos de entre los cuales destacó la disputa económica. Este comportamiento parece ser similar al descrito en otras regiones próximas, a pesar de regirse por una legislación diferente. El conflicto alcanzó a todos los estratos sociales sin reparar en localizaciones geográficas, ni en usos y costumbres, ni en el modo de explotar los recursos económicos, ni en el estatus social de los protagonistas, afectando por igual al mundo rural y al urbano. La «raíz del mal», del conflicto, disfrazada de ambición desmedida o de instinto de supervivencia, aparece en la documentación procesal como algo consustancial al ser humano, casi genético - en los herederos de Caín-. En otros muchos casos, sin duda los más, el cariño, la solidaridad o la racionalidad se impusieron, pero-como tantas veces ocurre con las cosas positivas- aquellos hicieron menos ruido y dejaron menor rastro documental. No obstante la ambición o el dinero no explican por sí solos todas las desavenencias y tensiones surgidas en las familias aragonesas. Podían estar o no presentes en momentos especialmente sensibles como, por ejemplo, en los preliminares del matrimonio, cuando familias enteras o miembros sueltos podían estorbar para hacerlo descarrilar por considerarlo deshonrosos o perjudicial. Los malos tratos, vicios como la bebida o el juego, infidelidades o la

56. Idem, caja 3.795-9, 1766.

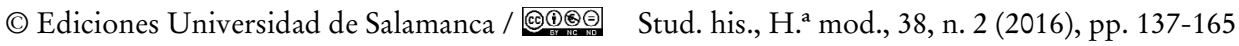


ENCARNA JARQUE MARTÍNEZ Y FRANCISCO JOSÉ ALFARO PÉREZ

HERENCIA, HONOR Y CONFLICTOS FAMILIARES EN EL ARAGÓN DEL SIGLO XVIII

simple incompatibilidad de caracteres son detonantes que repetidamente aparecen en los procesos analizados. En su rica casuística figuran todo tipo de causas de conflicto, así como de modos para dirimirlos. De todas ellas la económica fue la más habitual y, concretamente, relacionada con momentos muy precisos como eran los postreros a la disolución de una familia primigenia (las herencias).

\section{Bibliografía}

Alfaro Pérez, F. J. (Coord.): Familias Rotas. Zaragoza, 2014.

Alfaro Pérez, F. J.: «Ordenamiento foral y realidad socioeconómica de la mujer navarra (siglos XIV-XIX), en Salas Auséns, J. A. (Coord.): Logros en femenino. Mujer y conflicto social en el valle del Ebro, siglos XIV-XVIII. Zaragoza, Prensas Universitarias de Zaragoza, 2013, pp. 241-278.

Aragón Ruano, A.: «Familia, mujer y conflictividad en Guipúzcoa durante la Edad Moderna», Boletín de la Real Sociedad Bascongada de Amigos del País, Tomo 67, n. ${ }^{\circ} 1-2,2011$, pp. 43-86.

Aragón Ruano, A.: «Mujeres y conflictividad familiar en Guipúzcoa durante el Antiguo Régimen», Obradoiro de Historia Moderna, 21, 2012, pp. 29-54.

Arbiol, A.: La familia regulada, Zaragoza, 1715 (ed. fac. con introducción de R. FernánDEZ, Zaragoza, Institución Fernando el Católico, 2000).

Baldellou Monclús, D. y Salas Auséns, J. A.: «Noviazgo y matrimonio en Aragón. Casarse en la Europa del Antiguo Régimen», Revista de Historia Moderna, Anales de la Universidad de Alicante, . $^{\circ}$ 34, 2016.

BALDELLOU MonClús, D.: «Los conflictos matrimoniales en las familias y estructuras de poder del Alto Aragón en el siglo xviI», Tiempos Modernos: Revista Electrónica de Historia Moderna, 8:9, 2014, 29 pp.

BALDELlou Monclús, D.: «El valor de los esponsales: Estrategias y conflictos familiares entre la montaña y el llano aragonés (s. XviII)», en Pérez Álvarez, M. J. y Martín García, A. (Eds.), Campo y campesinos en la España Moderna. Culturas políticas en el mundo hispano. Madrid, Fundación de Historia Moderna, 2012, pp. 1038-1048.

BALDELlou Monclús, D.: «La sombra de los fueros es alargada. El proceso de manifestación tras los decretos de Nueva Planta», en Colás Latorre, G. (Coord.): Estudios sobre la sociedad aragonesa en la Edad Moderna. Zaragoza, 2015, Mira Editores, pp. 181-230.

Beauvalet-Boutouyrie, S.: Être veuve sous l'Ancien Régime, París, Belin, 2001.

BirRiel, M.: «El cónyuge supérstite en el derecho hispano», Chronica Nova, 34, 2008, pp. 3-44.

BorXados, R.: “"Cuñados no son parientes sino accidentes”. Conflictos familiares en torno a la herencia de Cochangasta. (La Rioja, siglo xvIII)», Anuario del CEH, n. ${ }^{\circ}$ 1, 2001, pp. 39-61.

Borello, B.: «Annodare e sciogliere. Reti di relazioni femminili e separazioni a Roma (xvII-XVIII secolo)», Quaderni Storici, 111, n. ${ }^{\circ}$ 3, diciembre 2002, pp. 617-648.

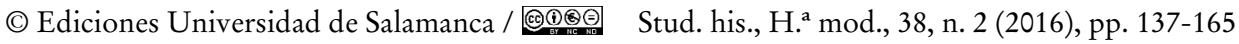


ENCARNA JARQUE MARTÍNEZ Y FRANCISCO JOSÉ ALFARO PÉREZ

HERENCIA, HONOR Y CONFLICTOS FAMILIARES EN EL ARAGÓN DEL SIGLO XVIII

Bossy, J. (Ed.): Disputes and Settlements. Law and Human Relations in the West. Cambridge,

Cambridge University Press, 1983.

Casey, J.: «La conflictividad en el seno de la familia», Estudis, 22, 1996, pp. 9-25.

Charageat, M.: La délinquance matrimoniale. Couples en conflit et justice en Aragon. París, Publications de la Sorbonne, 2011.

Collomp, A.: «Conflits familiaux et groupes de résidence en haute Provence», en Annales ESC, 36, 3, 1981, pp. 408-425.

Córdoba de la Llave, R. (Coord.): Mujer, marginación y violencia entre la Edad Media y los tiempos modernos. Córdoba, 2006.

Crawford, P. y Dolan, F.: Marriage and Violence. The Early Modern Legacy. U. Pennsylvania Press, 2008.

CuArtero Arina, R.: Mujeres transgresoras: el delito sexual en la Zaragoza de los siglos XVI $y$ XVII. Tesis doctoral dirigida por E. Solano Camón y defendida en la Universidad de Zaragoza el año 2013.

FAlcón Pérez, M. I.: «Procesos por causas matrimoniales en Zaragoza en la Baja Edad Media y Primer Renacimiento», Aragonia Sacra, IX, 1994, pp. 208-252.

Falcón Pérez, M. I., y Motis Dolader, M. A.: Procesos criminales en el Arzobispado de Zaragoza. Zaragoza, Diputación general de Aragón, 2000.

Fargas Peñarocha, M.: «De conflictos y acuerdos: la estrategia familias y el juego del género en la época moderna», Anuario de Hojas de Warmi, n. ${ }^{\circ}$ 16, 2011, pp. 1-18.

Fargas Peñarocha, M.: «Hacia la autoridad contestada: conflictividad por la dote y familia en Barcelona (XVI-XVII)», en Investigaciones Históricas, 30, 2010, pp. 99-118.

Fauve-Chamoux, A.: «El matrimonio, la viudedad y el divorcio», en Kertzer, D. I. y BARBAGLI, M. (Comps.): La vida familiar a principios de la era moderna (1500-1789). Barcelona, 2002, pp. 331-376.

Ferraro, J.: Marriage Wars in Late Renaissance Venice. Oxford, Oxford University Press, 2001.

García González, F. y Gómez Carrasco, C.: «Tensión familiar y conflictividad social en la España meridional: el ejemplo de Albacete, 1700-1830», en Bellavitis, A. y Снавот, I. (Coords.): La justice des familles:autour de la transmission des biens, des savoirs et des pouvoirs (Europe, Nouveau monde, XIIe-XIXe siècles). Ecole Française de Rome, 2011, pp. 263-286.

García González, Fco.: «Las dimensiones de la convivencia. Ciudades y hogares en España, siglos XVIII-XIX», en Revista de Historiografía, n. ${ }^{\circ}$ 16, 2012, pp. 24-43.

García herrero, C.: «Viudedad foral y viudas aragonesas a fines de la Edad Media», Hispania, LIII/2, 184, 1993, pp. 431-450.

Jarque Martínez, E. y Alfaro Pérez, F. J.: Caïn et Abel. Conflits fraternels au Royaume d'Aragon (XVIIIe et XIXe siècles), en BoudjaABA, F. (Coord.): Frères et soeurs du Moyen Âge à nos jours. Berna, Ed. Peter Lang, 2016, pp. 383-402.

Jarque Martínez, E.: «Derecho aragonés y pleitos familiares en el siglo XVIII», en Alfaro Pérez, F. J. (Coord.): Familias Rotas. Zaragoza, Prensas de la Universidad de Zaragoza, 2014, pp. 15-46.

(C) Ediciones Universidad de Salamanca / ®@ Stud. his., H. ${ }^{a}$ mod., 38, n. 2 (2016), pp. 137-165 
ENCARNA JARQUE MARTÍNEZ Y FRANCISCO JOSÉ ALFARO PÉREZ

HERENCIA, HONOR Y CONFLICTOS FAMILIARES EN EL ARAGÓN DEL SIGLO XVIII

Kagan, R.: Pleitos y pleiteantes en Castilla, 1500-1700. Salamanca, Junta de Castilla y León, p. 116.

Lorenzo Pinar, F. J.: «Actitudes violentas en torno a la formación y disolución del matrimonio en Castilla durante la Edad Moderna», en ForTeA, J. I., Gelabert, J. E. y Mantecón, T. A. (Eds.): Furor et rabies. Violencia, conflicto y marginación en la Edad Moderna. Santander, 2002, pp. 159-182.

Mantecón Movellán, T. A.: «Hogares infernales: una visión retrospectiva sobre la violencia doméstica en el mundo moderno", en Lorenzo Pinar, F. J. (Ed.): La familia en la historia. Salamanca, 2009, pp. 187-230.

Molinié-Bertrand, A.: «Les veuves dans l'Espagne classique» en Carrasco, R. (Coord.): Solidarités et sociabilités en Espagne (XVIe-XXe siècles). Annales Littéraires, Université de Besançon, 1991, pp. 267-275,

NAusia, A.: «El usufructo de viudedad navarro como recurso de supervivencia para las viudas(siglos XVI y XVII)», Iura Vasconiaem, 10, 2013, pp. 573-596.

Ortega López, M.: «Violencia familiar en el pueblo de Madrid durante el siglo XVIII», Cuadernos de Historia Moderna, 31, 2006, pp. 7-37.

Ortega López, M.: «La práctica judicial en las causas matrimoniales de la sociedad española del siglo XVIII", Espacio, tiempo y forma. Serie IV, Historia Moderna, n. ${ }^{\circ} 12,1999$, pp. 275-296.

Ortega LóPez, M.: «Protestas de las mujeres castellanas contra el orden patriarcal privado durante el siglo XVIII», Cuadernos de Historia Moderna, 19, 1997, Madrid, pp. 65-89.

Pascua SÁnchez, M. J J. de la: "Las relaciones familiares, historias de amor y conflicto», en Morant, I. (Dir.): Historia de las mujeres en España y América Latina, II, Madrid, Cátedra, 2005, pp. 287-317.

Pascua SÁnchez, M. J J. de la: «Desórdenes familiares en el siglo Xvin hispánico», en Serrano Martín, E. (Coord.): Felipe V y su tiempo: congreso internacional, Vol. 1, 2004, pp. 631-652.

Pascua SÁnchez, M. J J. de la: «Violencia y familia en la España del Antiguo Régimen», en Estudis: Revista de historia moderna, 28, 2002, pp. 77-102.

Pascua SÁnchez, M. J. Je la: «Violencia y familia en la España moderna», en Actas de la XI reunión científica de la Fundación Española de Historia Moderna, Granada, 2012. pp. 127-157.

Pellegrin, N. y Winn, H.: Veufs, veuves et veuvage dans la France d'Ancien Régime. París, Honoré Champion, 2003.

Ramiro Moya, F. y Salas Auséns, J. A.: «Mujer y transmisión de la propiedad en el Aragón moderno", en Salas Auséns, J. A. (Coord.): Logros en femenino. Mujer y conflicto social en el valle del Ebro, siglos XIV-XVIII. Zaragoza, Prensas Universitarias de Zaragoza, 2013, pp. 15-74.

Rey Castelao, O.: «Femmes et héritage en Espagne au Xvire siècle: Stabilité légale et changements réels», XVIIe. Siècle, 244, 61 année, n. o 3, 2009, pp. 457-458.

Salas Auséns, J.: «La Cenicienta no era un cuento», en Alfaro Pérez, F. J. (Coord.), Familias Rotas. Zaragoza, 2014, pp. 169-208.

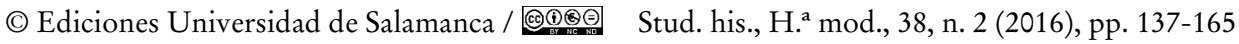


Salas Auséns, J. A.: «Pero si ..., y si ..., por si ...: Asegurar la pervivencia de la casa en el Alto Aragón en la Edad Moderna», Obradoiro de Historia Moderna, n. ${ }^{\circ} 24,2015$, pp. 225-255.

Savall, P. y Penén, S.: Fueros, Observancias y Actos de Corte del reino de Aragón. Zaragoza, 1866 (ed. fac. Zaragoza, El Justicia de Aragón, 1991).

STONE, L.: Broken Lives: Separation and Divorce in England 1660-1857. Oxford, 1993.

UsunÁriz Garayoa, J. M. a: «Cuando la convivencia es imposible: Los pleitos de discordia entre padres e hijos (Navarra, siglos XVI-XVII)», en UsunÁrIZ GARAYOA, J. M. a y GARCíA Bourrellier, R. (Eds.): Padres e hijos en España y el mundo hispánico. Siglos XVI y XVII. Madrid, 2008.

(C) Ediciones Universidad de Salamanca / @®@@ Stud. his., H. ${ }^{a}$ mod., 38, n. 2 (2016), pp. 137-165 
